\title{
Retraction Note: River wetland ecological forecast and diversified development of university entrepreneurship education based on matching tracking
}

\author{
Xiao Liu ${ }^{1} \cdot$ Xiaoping Shi ${ }^{1}$
}

Published online: 16 November 2021

(c) Saudi Society for Geosciences 2021

Retraction Note: Arabian Journal of Geosciences (2021) 14: 1714

https://doi.org/10.1007/s12517-021-07956-w

The Editor-in-Chief and the Publisher have retracted this article because the content of this article is nonsensical. The peer review process was not carried out in accordance with the Publisher's peer review policy. Author Xiaoping Shi has not responded to correspondence regarding this retraction. The Publisher has not been able to obtain a current email address for author Xiao Liu.

The original article can be found online at https://doi.org/10.1007/ s12517-021-07956-w

Xiaoping Shi

1x45603@126.com

1 School of Management, Hebei Chemical \& Pharmaceutical College, Shijiazhuang 050026, Hebei, China 